Proc. of the International Conference on Mechanochemistry and Mechanical Alloying, Kraków, Poland, June 22-26, 2014

\title{
Structural Identification of Polymer Nanocomposites
}

\author{
M. Bilewicz, K. Labisz, T. TAŃski, J. Konieczny and M. Górniak
}

Silesian University of Technology, Faculty of Mechanical Engineering, S. Konarskiego 18a, 44-100 Gliwice, Poland

\begin{abstract}
Composites and nanocomposites as commercially used engineering materials with continuous development, are important for rising market and industry needs. Significant role is played by polymers, whose consumption increases every year, thanks to low cost of production, economical processing and broad scope of material composition possibilities, including nanomaterials and basing on them nanocomposites. Nanocomposites, using power of nanotechnology, may improve physical, chemical and mechanical properties, comparing to composites. Investigation of structure and properties of such materials is necessary to obtain knowledge about phenomena at micro and nanoscale and gives opportunity to design and control structure, because the properties of any material depend on its matter. Polymer matrix nanocomposites are interesting and very promising class of polymer composites. Investigation of structure development due to different heat treatment and under different processing condition of injection molded specimens of polypropylene and montmorillonite composition has been performed. Dispersion of nanoreinforcement, in the shape of 2:1 layer silicates, was observed under transmission and scanning electron microscope. Application of advanced technology of multiplication of oriented layer mostly reinforcing and orienting micro and nanoparticles along polymeric specimen, allowed to obtain several layers and significantly reinforced material. Light microscope has been used for observation layered zone, visible just in polarization mode.
\end{abstract}

DOI: 10.12693/APhysPolA.126.895

PACS: 36.20.-r, 61.41.+e, 81.20.-n, 81.40.Gh, 81.40.Lm, 81.70.-q, 81.70.Bt, 82.35.-x

\section{Introduction}

Research and development centres worldwide attempt to improve existing structures of engineering materials or create new ones, basing on neural networks and artificial intelligence tools, looking for new design of materials including alloys and composites. The main objective is largely to improve properties of materials [1-6]. Weight-to-strength ratio is one of the strategic features of materials' assortment, whereby can be created light and tough material, meeting the requirements of contemporary constructions and vehicles. Comparison of the relative strength of selected engineering materials shows that composites based on polymer matrix and reinforced with fibres can expose high values (Fig. 1) [7, 8].

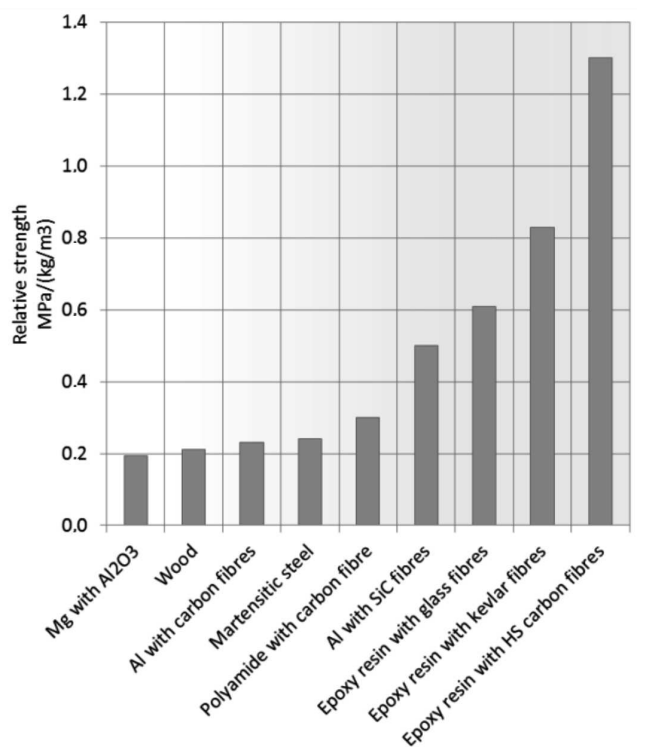

Fig. 1. Relative strength of selected engineering materials [14].
Branch experts and futurologists predict growing evolution of plastic market, showing contiguous growth of demand of plastics until year 2020, reaching level equal to 300 million tons (50 million tons more than in 2010) and consumption of polymeric materials will reach more than $120 \mathrm{~kg}$ per person [8]. Production of polymeric materials focuses especially on packaging, building and automotive industry. These sectors exhibit particular activity in consumption and exploration of new products (Fig. 2) [8-13].

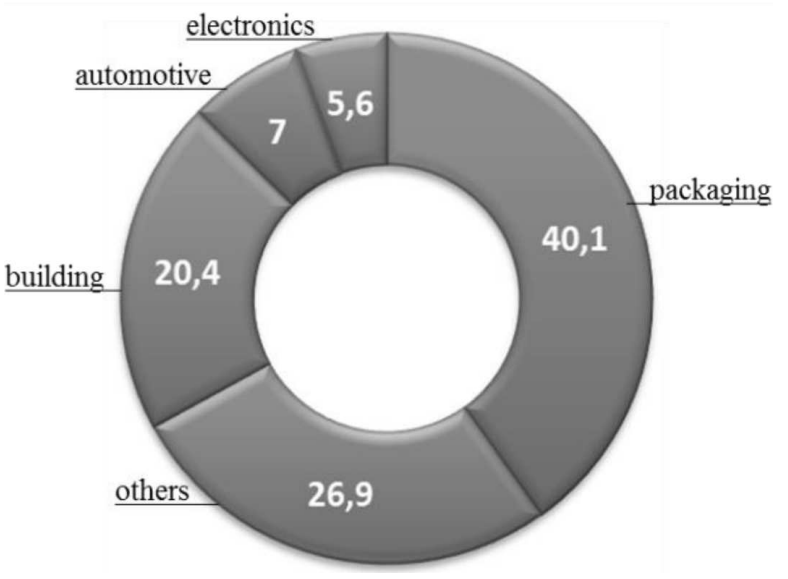

Fig. 2. Most active sectors in plastics application in Europe, values in \% [12].

Production of polymeric components, as well as composites based on polymeric matrix, uses mostly injection moulding processes, including extrusion, extrusion blow moulding, injection blow moulding, rotational moulding, compression moulding, resin transfer moulding, steam pressure forming, co-injection moulding, gas assisted injection moulding, reaction injection moulding, vacuum 
injection moulding, sheet thermoforming and others. This type of processing is economically attractive and fast for massive production covering almost $30 \%$ of worldwide expenditure of all plastics and manufacturers still search for new processing techniques and create new trends $[7,8,14-21]$.

The properties of polymers and basing on them composites and nanocomposites arise from material combination and phenomena accompanying the formation of the morphology, for instant dispersion of second phase particles, orientation of particles, interfacing with the matrix. Moreover the miscellany of structure can be defined by the particle size, size ratio and dispersion level inside matrix and control over distribution and exfoliation/intercalation of particles can be achieved by choose of right processing technique and control of processing parameters [21-26].

Reinforcing of polymer composites by different particles (by size and size ratio) is important direction to improve properties and one of these directions is compounding polymer composites basing on nanofillers embedded inside polymer matrix. Melt mixing through extruding and forming by injection molding is one of most common techniques. There are many possibilities of forming nanocomposites, but the main goal for all techniques is to reduce number of agglomerates by breaking them up, their good exfoliation or intercalation and improvement of mechanical properties. Fragmentation of agglomerated particles and well distribution can be obtained through high shearing during forming processing. This element of production is satisfied by non-conventional injection molding process, used in this experiment, where in the shear zone at boundaries of the layers, appears high shear rate, strengthened by moving of melt flow front along quasi-frozen layer $[4,19,27]$.

\section{Experimental}

The experimental was performed on injection molding machine and different material composites, basing on polypropylene (PP), polycarbonate (PC) and montmorillonite (MMT), accordingly to Table I [28, 29].

TABLE I

Ratio of materials used in experiment.

\begin{tabular}{c|c|c}
\hline \hline Composite & $\begin{array}{c}\text { Matrix } \\
{[\mathrm{wt} \%]}\end{array}$ & $\begin{array}{c}\text { Reinforcement } \\
{[\mathrm{wt} \%]}\end{array}$ \\
\hline $\mathrm{PP}$ & 100 & - \\
$\mathrm{PP} / \mathrm{PC}$ & 70 & 30 \\
$\mathrm{PP} / \mathrm{PC} / \mathrm{MMT}$ & 67 & $30 / 3$ \\
$\mathrm{PP} / \mathrm{MMT} \mathrm{3}$ & 97 & 3 \\
$\mathrm{PP} / \mathrm{MMT} \mathrm{5}$ & 95 & 5 \\
$\mathrm{PP} / \mathrm{MMT} \mathrm{10}$ & 90 & 10
\end{tabular}

Material specification given by supplier and thermo gravimetric test result determining melt temperature are presented in Table II.
TABLE II

Materials used in experiment.

\begin{tabular}{cll}
\hline \hline PP & Moplen HP 501M & $\begin{array}{l}\text { density: } 0.9 \mathrm{~g} / \mathrm{cm}^{3}, \\
\text { melt temp: } 200{ }^{\circ} \mathrm{C}\end{array}$ \\
\hline \multirow{2}{*}{ PC } & Lexan 123 & $\begin{array}{l}\text { density: } 1.2 \mathrm{~g} / \mathrm{cm}^{3}, \\
\text { melt temp: } 240{ }^{\circ} \mathrm{C}\end{array}$ \\
\hline \multirow{2}{*}{ MMT } & \multirow{2}{*}{ Nanofil 5} & $\begin{array}{l}\text { density: } 1.8 \mathrm{~g} / \mathrm{cm}^{3}, \\
\text { melt temp: }>390^{\circ} \mathrm{C}\end{array}$ \\
\hline
\end{tabular}

Polycarbonate were used as particles with micrometric scale and montmorillonite as nanosized clay with platelet shape and layered structure containing two tetrahedral sheets attached to octahedral one (Figs. 3, 4). MMT contains atoms of silica, aluminium and magnesium which is included in formula $\mathrm{M}_{x}\left(\mathrm{Al}_{4-x} \mathrm{Mg}_{x}\right) \mathrm{Si}_{8} \mathrm{O}_{20}(\mathrm{OH})_{4} \mathrm{AlO}_{6}$.

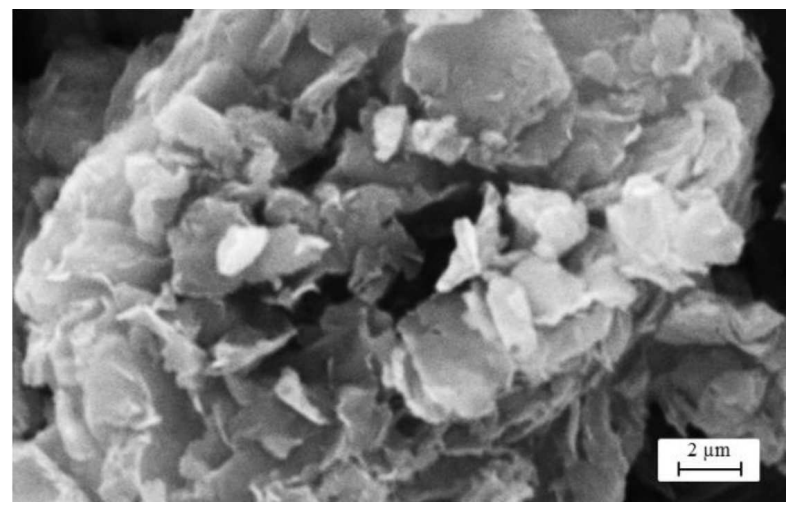

Fig. 3. Particles of MMT in a platelet shape.

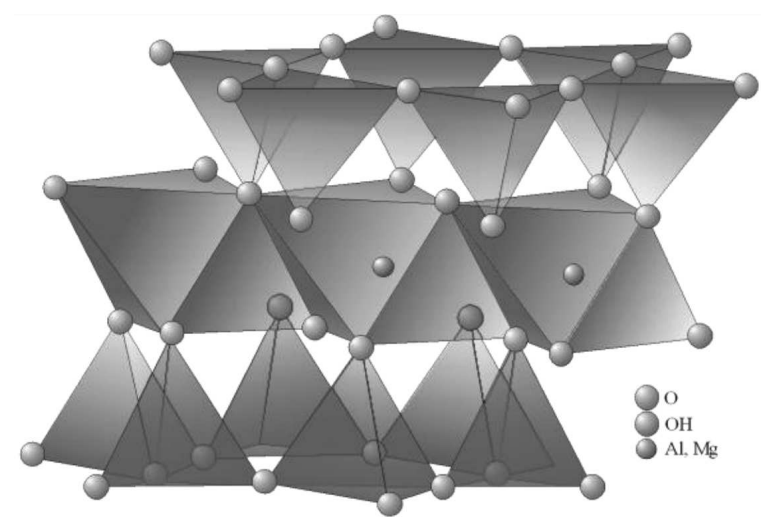

Fig. 4. Schematic illustration of atoms arrangements in a typical MMT smectite clay with tetrahedraloctahedral sheets in proportion $2: 1$.

Experimental plan was basing on the change of the main changeable parameters of conventional injection moulding (CIM) and non-conventional injection moulding $(\mathrm{N}-\mathrm{CIM})$ process, that is melt temperature $\left(\mathrm{T}_{\mathrm{m}}\right)$, stroke number (SN) of pistons connected to the mould, whose movement consisted on alternating extension and 
retraction of the melt in the mould cavity, and stroke time (ST) between movements of the pistons, accordingly to Table III.

TABLE III

Set of parameters for N-CIM and CIM.

\begin{tabular}{c|c|c|c|c}
\hline \hline \multirow{2}{*}{ Technology } & \multirow{2}{*}{ Set } & \multicolumn{3}{|c}{ Variables of the processing } \\
& & $\mathrm{Tm},\left[{ }^{\circ} \mathrm{C}\right]$ & $\mathrm{ST},[\mathrm{s}]$ & SN \\
\cline { 3 - 5 } & 1 & 240 & - & - \\
\hline \multirow{2}{*}{ CIM } & 2 & 280 & - & - \\
\hline \multirow{5}{*}{ N-CIM } & 3 & 240 & 1 & 3 \\
& 4 & 240 & 3 & 3 \\
& 5 & 240 & 1 & 12 \\
& 6 & 240 & 3 & 12 \\
& 7 & 280 & 1 & 3 \\
& 8 & 280 & 3 & 3 \\
& 9 & 280 & 1 & 12 \\
& 10 & 280 & 3 & 12
\end{tabular}

The melt temperature was set accordingly to suppliers guidelines and verified by thermogravimetric analysis for MMT particles to confirm that degradation temperature of nanoparticles is not lower than melt temperature of the matrix.

This type of injection was called in the article as $\mathrm{N}-\mathrm{CIM}$. Conventional injection molding was performed as basing technique for comparison purpose. Shearing effect which assist during injection molding influences on the structure. In the specimen cross-section performed by conventional injection molding, highest level of shear stress exists in the skin layer (the outer part). This phenomenon, mentioned in literature by Rosato and Utracki $[3,7]$, considers fact that particles located closer to skin are extended due to faster cooling and simultaneously strong shearing. In the technique used in the experiment with special pistons, this effect is multiplicated, and movements induce high shearing which affects both micro and nanoparticles.

Specimens were tested by 3-point bending test with crosshead speed $10 \mathrm{~mm} / \mathrm{min}$ (according to the ASTM E399 standard) at controlled room temperature $\left(23{ }^{\circ} \mathrm{C}\right)$. Fractured specimens were previously notched in a Ceast notch cutter type 6816 with a notch depth of $a=$ $6.35 \mathrm{~mm}$ and then sharpened with razor blade. For each processing run there were tested at least five specimens to avoid error. The fracture energy was calculated by a $J$-integral value, $J_{0}$, directly derived from the integration of the load-displacement diagram via the total energy, $U$ :

$$
J_{0}=\frac{\eta_{\mathrm{e}} U}{B(W-a)},
$$

where $\eta_{\mathrm{e}}$ is a geometric factor $(\eta \mathrm{e}=2.03$ for a single edge notched beam, SENB, = 0.5), $B$ and $W$ are the specimen thickness and width, respectively and $a$ is the notch depth.
The fracture surfaces were observed by scanning electron microscopy (SEM) at voltage of $15 \mathrm{kV}$, after coating the broken specimens by a thin gold layer.

Thin slices of $20 \mu \mathrm{m}$ cut on Microtom Anglia and immersed in Canadian balsam at glass plate, were observed by polarized light on Olympus light microscope type $\mathrm{BH} 2$ additionally equipped by the Olympus digital camera DP11. This observation allowed evaluation of the sheared multilaminar zone in the microstructure.

\section{Results}

Before observation of nanoparticles and its influence on the structure, phenomena of dispersion of $\mathrm{PC}$ micro particles inside immiscible $\mathrm{PP} / \mathrm{PC}$ composite were observed (Figs. 5, 6). Due to the immiscibility of polypropylene and polycarbonate blend drops of polycarbonate can be particularly localized at the interface. Moreover, control of empirical critical capillary number may give possibility to elongate drops without breaking, and such deformation can be induced during developed injection process, while polymer is subjected to a large shearing forces [30-32].

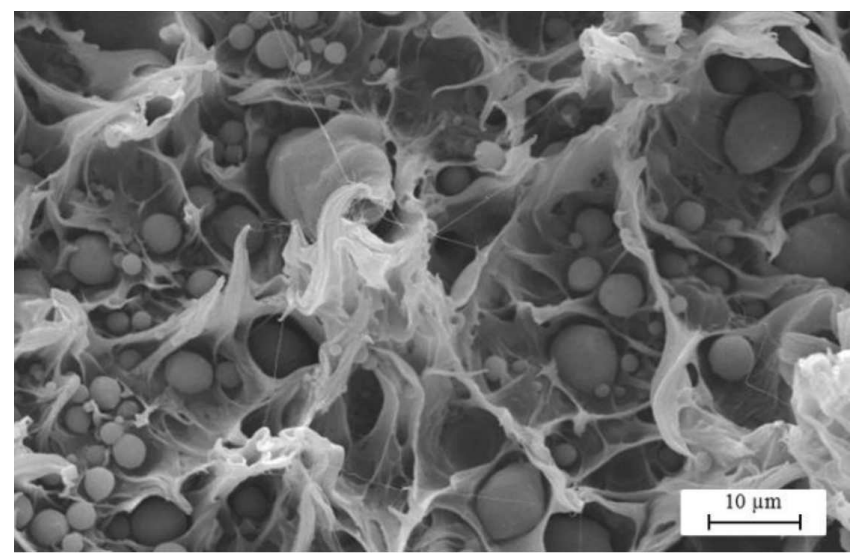

Fig. 5. Particles of PC inside PP matrix.

Preliminary observation of distribution of $\mathrm{PC}$ micro particles, easy to observe on light microscope, and supported by cyclohexanone solvent for clear identification, helped in understanding phenomena of energy absorption during fracture test and helped in the selection of particular parameters of injection process during many trials, as well as backpressure, holding pressure and cooling temperature of the mold.

In the next step effect of shearing on the morphological development of reinforced and non-reinforced polypropylene was observed.

For this reason two techniques of injection molding were compared - conventional and non-conventional. It has been reported that extensional stress fields will vary along the cross-section of the molding, resulting in the development of a complex microstructure and reinforcement behaviour inside the moulding, which affects 

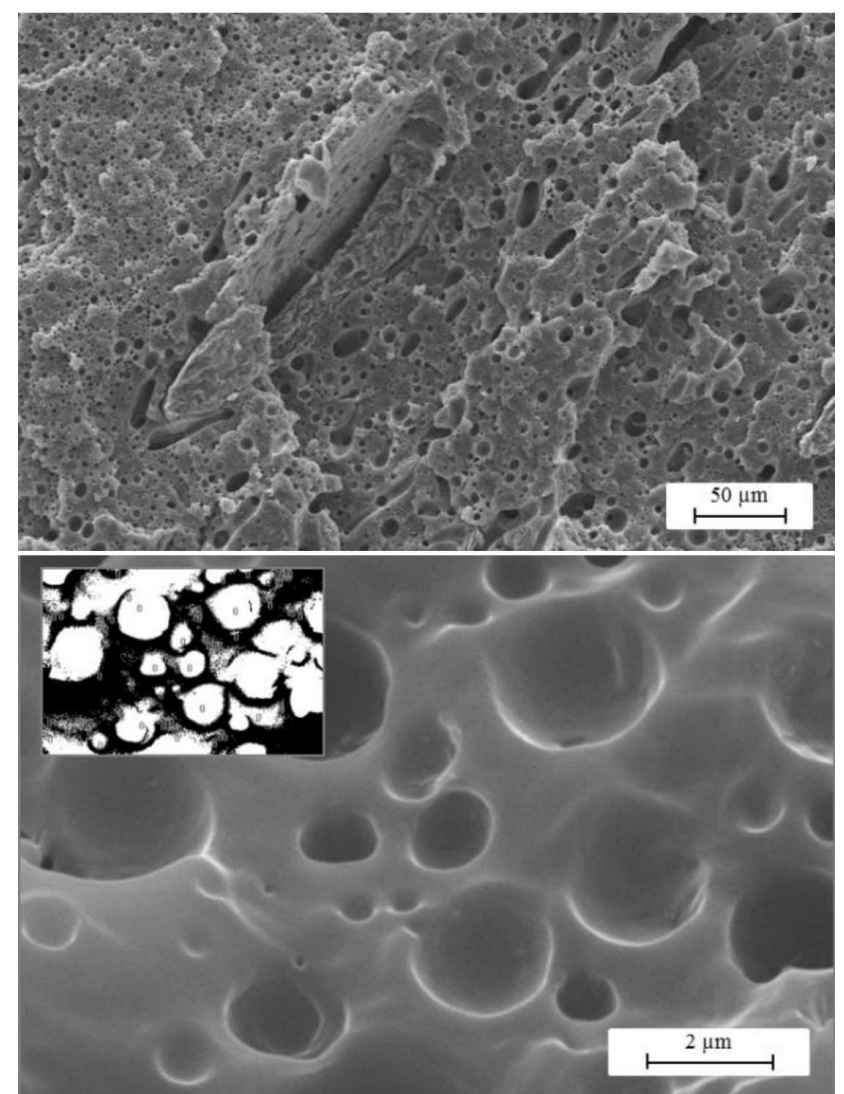

Fig. 6. Particles of PC inside PP matrix after using cyclohexanone - solvent of $\mathrm{PC}$; in the corner visible detected particles after using image analysis software.

the mechanical properties. Core, which occupies internal part of specimen, multi-layered zone and skin which appears on outer part of specimen (Fig. 7) depends on processing parameters. In the specimens performed by $\mathrm{N}-\mathrm{CIM}$, core occupies $52 \%$, the rest belongs to shear zone, including skin. It can be compared to CIM, where the skin, which reinforces material mostly, occupies just $10 \%$. Visible difference between CIM and N-CIM morphology is also the shrinkage appearing in specimens processed by CIM, which is 10 times lower, thanks to the reciprocated movements of pistons which affect on tight fulfilling the capacity of the mould (Figs. 7-9).

Polypropylene microstructure visible on the crosssection, shows difference between core containing spherulities and skin with oriented particles. Also visible shrinkage of the whole specimen can be reported (Fig. 8).

For specimens performed by N-CIM there has been reported more accurately mapping of the cavity shape and shrinkage of $0.2-0.3 \%$ (Fig. 9 ).

For neat PP specimens performed by N-CIM increment of the SN (set 6 and 7, Table III) and simultaneously $T_{\mathrm{m}}$ together with $\mathrm{SN}$, created and significantly developed multi-layer sheared zone, reaching $45 \%$ of the sample volume (Figs. 9, 10).

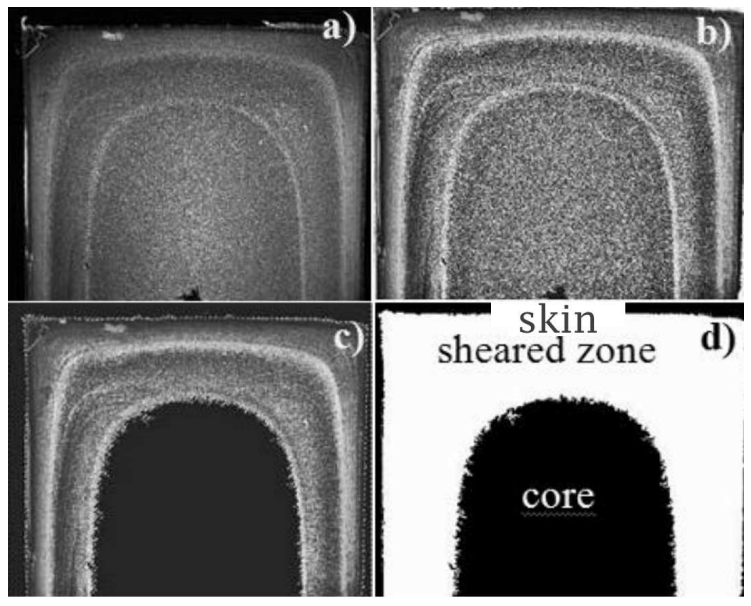

Fig. 7. Computer aided image analysis and area calculations of cross section; specimen obtained by N-CIM: (a) direct image from polarized light microscopy, (b) contrast and gamma correction, (c) edge detection, (d) mask overlapping.

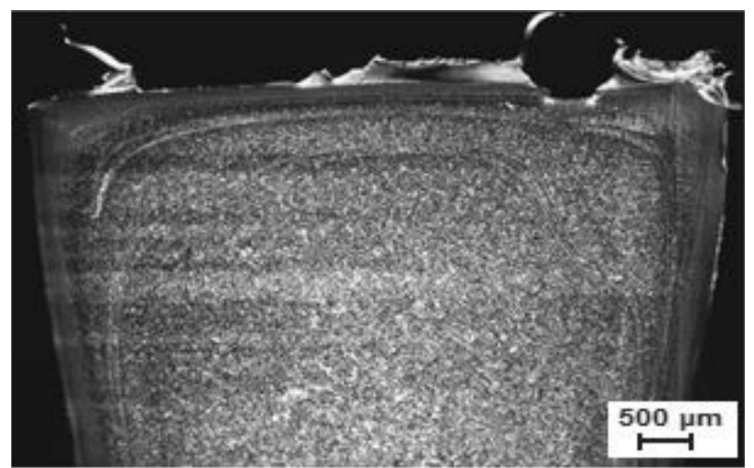

Fig. 8. Cross-section of the neat PP specimen performed by $\mathrm{CIM}$ in $280^{\circ} \mathrm{C}$.

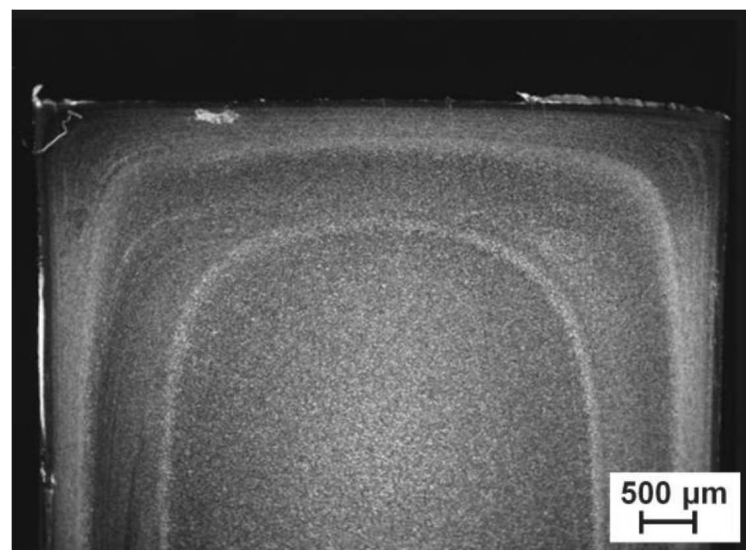

Fig. 9. Cross-section of the neat PP specimens performed by N-CIM, set 5 (Tm/ST/SN: $240 / 1 / 12)$ subsequently to Table III. 


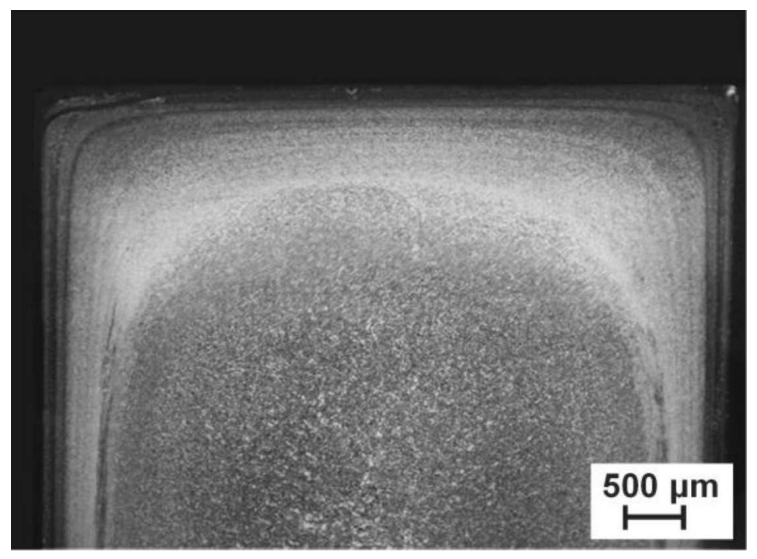

Fig. 10. Cross-section of the neat PP specimen performed by N-CIM, set 8 (Tm/ST/SN: 280/3/12) subsequently to Table III.

The next step in the experiment was the addition of nanoparticles, in accordance with the phenomenon of high shear stress in outer part of the specimen. General problem with the nanoparticles is tendency to create the agglomerates. Shearing effect, which appears in the injection process close to the outer skin of the molding due to the solidification phase of polymer, and multiplied in the N-CIM technique, which can be controlled by SN and ST gives possibility to break MMT agglomerates. For better understanding research was performed for four nanocomposites (Table I) at 10 different sets (Table III). During investigation it has been reported that volume of multilayered zones increases for nanocomposites with $1,3,5$ and $10 \mathrm{wt} \%$ of MMT, performed at higher values of ST and SN (set 6 and 10), accordingly to increment of stroke numbers for both melt temperatures (Figs. 11-14).

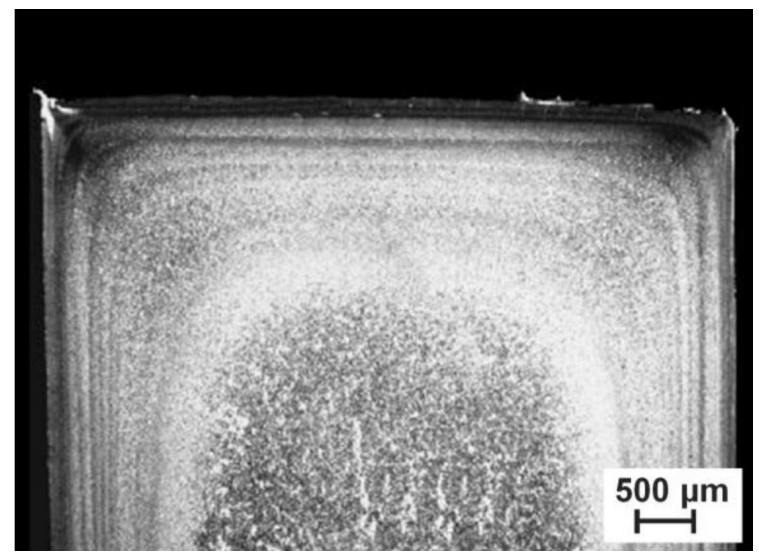

Fig. 11. Cross-section of the $\mathrm{PP} / \mathrm{MMT} 1$ specimens performed by $\mathrm{N}-\mathrm{CIM}$, set $6(\mathrm{Tm} / \mathrm{ST} / \mathrm{SN}: 240 / 3 / 12)$ subsequently to Table III.

Addition of $10 \mathrm{wt} \%$ of MMT to polypropylene, saturated polymer matrix and enabled creation of agglomerates, visible at micro level, which are not enough solid and during cracking they do not block and retard crack

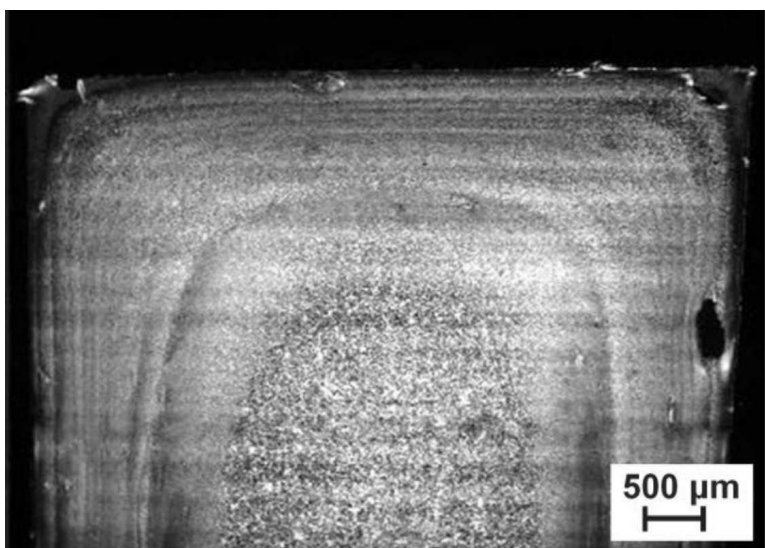

Fig. 12. Cross-section of the $\mathrm{PP} / \mathrm{MMT} 3$ specimens performed by N-CIM, set $6(\mathrm{Tm} / \mathrm{ST} / \mathrm{SN}: 240 / 3 / 12)$ subsequently to Table III.

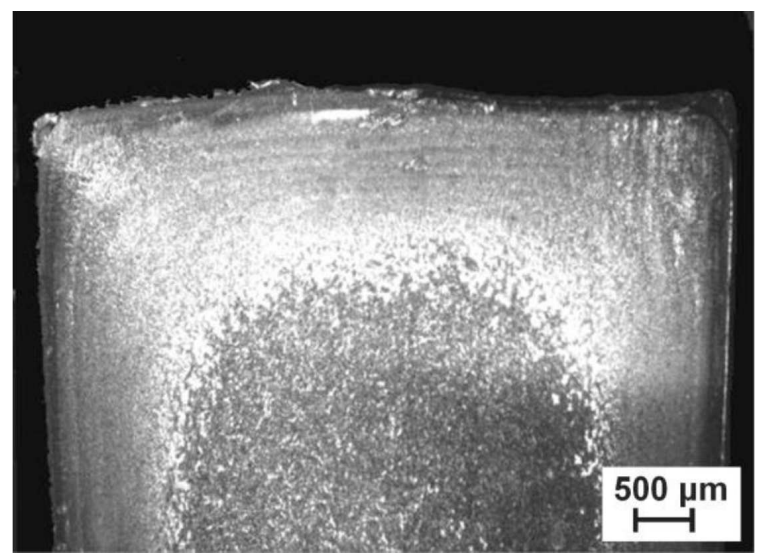

Fig. 13. Cross-section of the $\mathrm{PP} / \mathrm{MMT} 5$ specimens performed by N-CIM, set $4(\mathrm{Tm} / \mathrm{ST} / \mathrm{SN}: 240 / 3 / 12)$ subsequently to Table III.

propagation, so they are undesirable in the structure, weakening the material (Fig. 14).

Investigation of the energy absorption during the fracture test complemented information about the strengthening mechanisms in the structure (Fig. 15). Diagram shows 10 different sets, numbered 1-10 accordingly to Table III, and results of energy absorption of five composites and neat PP for comparison. It can be reported that maximum reinforcement was achieved for specimens of PP with nanoparticles, especially for 6 and 10 set. Addition of nanoparticles to composite of $\mathrm{PP} / \mathrm{PC}$ did not improve mechanical properties. Further investigation has been discontinued.

To verify reinforcing mechanism, especially for nanocomposites PP/MMT with 3 and 5 wt\% of MMT, which represent the highest toughness, SEM observation was performed. The best properties were obtained for nanocomposite PP/MMT 3 and 5 wt\% with a most developed structure - set 6 and 10 performed by N-CIM (Fig. 16). 


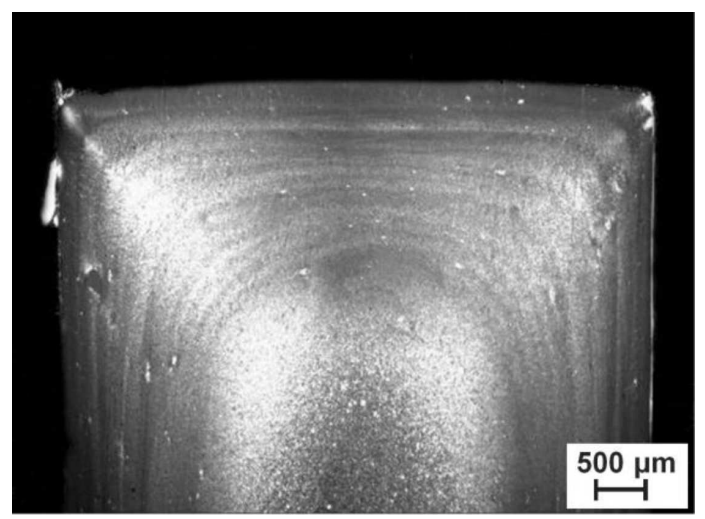

Fig. 14. Cross-section of the PP/MMT 10 specimens performed by $\mathrm{N}-\mathrm{CIM}$, set $6(\mathrm{Tm} / \mathrm{ST} / \mathrm{SN}: 240 / 3 / 12)$ subsequently to Table III.

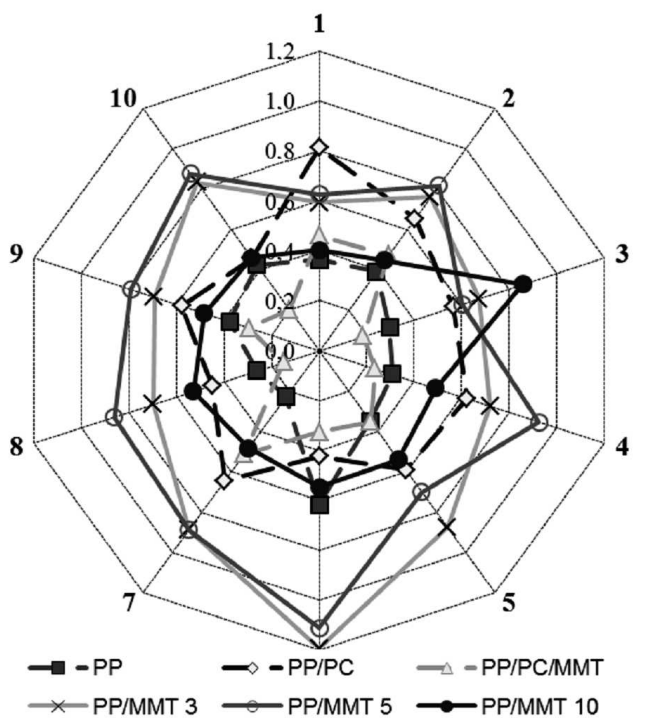

Fig. 15. Energy absorption diagram [J] after 3-point bending fracture test for neat $\mathrm{PP}$ and 5 composites performed by CIM and N-CIM techniques, for 10 different sets of processing parameters, accordingly to Table III.

For specimens of PP/MMT $3 \%$ performed by CIM, there can be reported good dispersion inside polypropylene matrix with visible tendency to formation of montmorillonite agglomerates, with size of $5 \mu \mathrm{m}$, for both processing temperatures (Fig. 16).

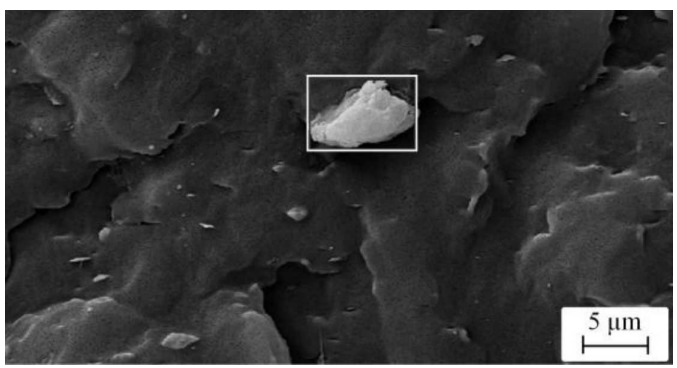

Fig. 16. MMT agglomerate inside polypropylene matrix.
Application of N-CIM technology induced high shear rates, during solidification phase of polymer and splatted agglomerates, assuring intercalation of particles. Orientation of MMT galleries in accordance to polymer flow during alternating extension and retraction of the melt in the mould cavity has been achieved (Figs. 17, 18).

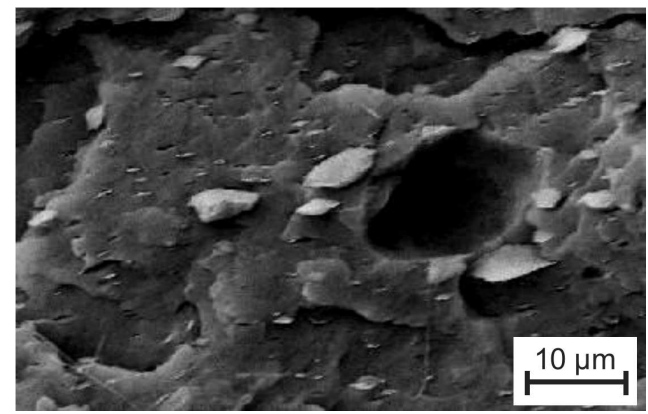

Fig. 17. Cross-section of the PP/MMT 3\% specimen performed by CIM in $240{ }^{\circ} \mathrm{C}$; visible particular agglomerates of MMT platelets.

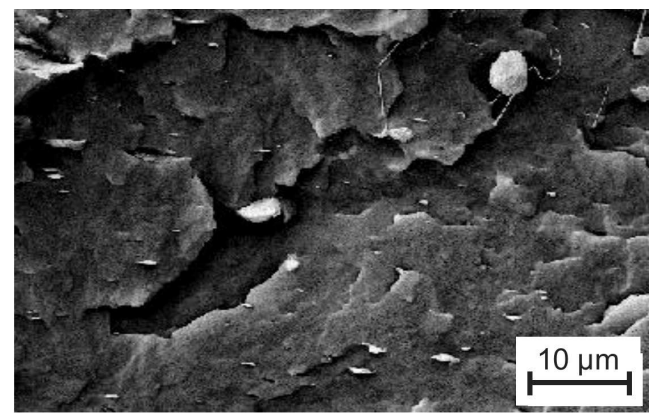

Fig. 18. Cross-section of the PP/MMT 3\% specimen performed by CIM in $280^{\circ} \mathrm{C}$; visible particular agglomerates of MMT platelets.

Best intercalation was achieved for nanocomposite $\mathrm{PP} / \mathrm{MMT} 3 \%$, processed under high level of ST and SN values (set 6 and 10) and verification of intercalation was possible at very high magnification using transmission electron microscopy, where clearly are visible galleries of MMT inside polypropylene matrix with interlayer distance equal to $2.7 \mathrm{~nm}$, measured by computer aided image analysis system (Fig. 19).

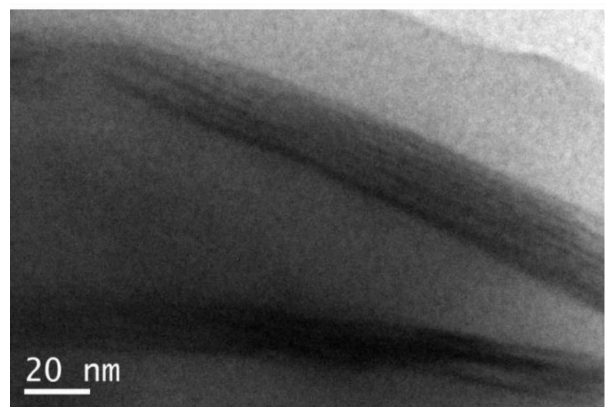

Fig. 19. Intercalation of MMT galleries approved by transmission electron microscopy. 


\section{Summary}

Nanocomposites based on PP significantly respond on use of N-CIM technique, resulting in significant reinforcement of structure and to multilayer zone. Observation of the structure confirmed unidirectional orientation and intercalated character of particles and confirmed that shear rates induced by $\mathrm{N}-\mathrm{CIM}$ technique support to break up agglomerates. To control this process further investigation is required. Increment of reinforcement comes from high surface area of intercalated nanoparticles and, on the other hand, unidirectionally oriented platelet particles effectively interlock crack propagation. Addition of nanoparticles improved strength of composites and thanks to advanced processing technology there has been obtained improvement of the structure, satisfying initial assumption of this work.

\section{References}

[1] R.F. Gibson, Composite Structures 92, 2793 (2010).

[2] E.J. Barbero, Introduction to Composite Materials Design, CRC Press, Boca Raton (FL) 2010.

[3] D.V. Rosato, M.G. Rosato, Injection Molding Handbook, 3rd ed., Kluwer Academic, New York 2000.

[4] S.S. Ray, M. Okamoto, Prog. Polym. Sci. 28, 1539 (2003).

[5] E.P. Giannelis, Adv. Mater. 8, 29 (1996).

[6] S.K. Kumar, R. Krishnamoorti, Ann. Rev. Chem. Biomol. Eng. 1, 37 (2010).

[7] L.A. Utracki, M.M. Dumoulin, P. Toma, Polym. Eng. Sci. 26, 34 (2004).

[8] Report of Plastics Europe Foundation, World in 2030 by Scientists and Futurologists, 2010.

[9] Report: www.plastech.pl/wiadomosci/artykul_2223_1/ Raport-o-tworzywach-swiatowa-produkcja-izapotrzebowanie.

[10] www.dl.dropbox.com/u/21130258/resources / InformationSheets/Plastics.htm.

[11] www.plasticstoday.com/articles/report-highlights-recov-ery-injection-molding-machine-sales.

[12] www.plasticseurope.pl/document/fakty-otworzywach-sztucznych-2010.aspx.
[13] www.plasticseurope.pl/cust/ documentrequest.aspx?DocID $=51139$

[14] A. Boczkowska, J. Kapuściński, Z. Lindermann, D. Witemberg-Perzyk, S. Wojciechowski, Composites, Oficyna Wydawnicza Politechniki Warszawskiej, Warsaw, 2003 (in Polish).

[15] D.B. Tchalamov, J.C. Viana, A.M. Cunha, Mechanical Properties of Two Component Injection Molded Parts, in: Proc. SPE ANTEC, Society of Plastics Engineers, San Francisco (CA, USA), 2002.

[16] A. Kumar, R.K. Gupta, Fundamentals of Polymer Engineering, Marcel Dekker, 2003.

[17] L.A. Dobrzański, M. Kowalski, J. Madejski, J. Mater. Process. Technol. 164, 1500 (2004).

[18] M. Bilewicz, J.C. Viana, A.M. Cunha, L.A. Dobrzański, Arch. Mater. Sci. Eng. 30, 69 (2008).

[19] M. Bilewicz, J.C. Viana, A.M. Cunha, Mater. Sci. Forum 514-516, 858 (2006).

[20] D.D.J. Rousseaux, N. Sallem-Idrissi, A.C. Baudouin, J. Devaux, P. Godard, J. Marchand-Brynaert, Polymer 52, 443 (2011).

[21] U.M. Attia, S. Marson, J.R. Alcock, Microfluid. Nanofluid. 7, 1 (2009).

[22] J.C. Viana, Polymer 45, 993 (2004).

[23] J. Stabik, Int. Polym. Process. 19, 350 (2004).

[24] G. Kalay, M.J. Bevis, J. Polym. Sci. Polym. Phys. 35, 415 (1997).

[25] J.C. Viana, N. Billon, A.M. Cucha, Polym. Eng. Sci. 44, 1522 (2004).

[26] S. Ghosh, J.C. Viana, R.L. Reis, J.F. Mano, Mater Sci. Eng. 490, 81 (2008).

[27] V. Mittal, Materials 2, 992 (2009).

[28] Handbook of Plastics Recycling, Ed. F. La Mantia, Rapra Technology Ltd, Shrewsbury 2002.

[29] K.E. Strawhecker, E. Manias, Chem. Mater. 12 , 2943 (2000)

[30] A.O. Baranov, E.V. Prut, J. Appl. Polym. Sci. 44, 1557 (2003).

[31] Y. Deyrail, R. Fulchiron, P. Cassagnau, Polymer 43 3311 (2002)

[32] M. Bilewicz, P. Palček, T. Tański, L. Markovicova, Arch. Mater. Sci. Eng. 64, 192 (2013). 